\title{
Parameterized Regional lonospheric Model: a new version
}

\author{
J. R. Souza ${ }^{1}$, P. C. P. dos Santos ${ }^{1}$, M. A. Abdu ${ }^{1}$, I. S. Batista ${ }^{1}$, A. Petry ${ }^{2}$, M. H. Woldeab ${ }^{1}$ \\ ${ }^{1}$ Instituto Nacional de Pesquisas Espaciais, Divisão de Aeronomia, São José dos Campos, SP, Brasil; \\ ${ }^{2}$ Centro Regional Sul de Pesquisas Espaciais - CRS/INPE, Santa Maria,RS, Brasil
}

Copyright 2011, SBGf - Sociedade Brasileira de Geofísica

This paper was prepared for presentation during the $12^{\text {th }}$ International Congress of the Brazilian Geophysical Society held in Rio de Janeiro, Brazil, August 15-18, 2011.

Contents of this paper were reviewed by the Technical Committee of the $12^{\text {th }}$ International Congress of the Brazilian Geophysical Society and do not necessarily represent any position of the SBGf, its officers or members. Electronic reproduction or storage of any part of this paper for commercial purposes without the written consent of the Brazilian Geophysical Society is prohibited.

\section{Abstract}

We have modified the Parameterized Regional lonospheric Model (PARIM) to include the longitudinal dependences. This model has been reconstructed using multidimensional Fourier series. To validate PARIM results, the equatorial electron densities/plasma frequencies for the $E$ and $F$ regions are compared with the values calculated by Sheffield Plasmaspherelonosphere Model (SUPIM). PARIM presents very good results, the old version inconsistencies for the F-region peak height (hmF2) near the geomagnetic equator during times of occurrence of the $\mathrm{F}_{3}$ layer were eliminated. PARIM results for the E-region peak density show excellent agreement with the observational values obtained during the conjugate point equatorial experiment (COPEX) campaign. foF2 and hmF2 calculated by PARIM show good agreement with the observations, except during daytime over Boa Vista and Campo Grande. Modelled TEC maps have also presented coherent values for the Brazilian sector.

\section{Introduction}

PARIM is based on theoretical climatology as given by the physics-based model of the ionosphere, the Sheffield University Plasmasphere lonosphere Model - SUPIM (Bailey and Sellek, 1990; Bailey et al., 1996, 1997). A detailed description of PARIM was published in the Journal of Advances in Space Research by Souza et al., 2010. Another model constructed also by means parameterization of a physical model was published by Daniell et al., 1995. An ionospheric application model considering such parameterization and data assimilation has been presented by Bishop et al. (2001). In the present study, we also compare the ionospheric plasma frequencies calculated by the new PARIM (PARIM second version) with those obtained during COPEX campaign (Reinisch et al., 2004).

\section{Preparation of the SUPIM results and model description}

SUPIM values of electron densities were obtained for thirteen levels of solar flux (F10.7 from 68 to 360), and for the $15^{\text {th }}$ day of each month. After, all the electron densities were converted to ionospheric plasma frequencies.

PARIM first version was developed applying one dimensional (1D) finite Fourier series analysis to the SUPIM results separately for each dependency (Souza et al., 2010). In this version, We have applied multidimensional (5D) Fourier using all dependencies which are solar flux, latitude, longitude, altitude and time. Our procedure is an extension of a 2D case applied to reconstruct an image as published by Nowak, 2008.

The 5D discrete Fourier transform equations used to construct our model are

$$
\begin{aligned}
& F\left(l_{1}, l_{2}, \ldots, l_{5}\right)=\sum_{j_{1}=0}^{N_{1}-1}\left(\sum _ { j _ { 2 } = 0 } ^ { N _ { 2 } - 1 } \left(\ldots \left(\sum _ { j _ { 5 } = 0 } ^ { N _ { 5 } - 1 } \left(f\left(j_{1}, j_{2}, \ldots, j_{5}\right) e^{-i \frac{2 \pi l_{1} j_{1}}{N_{1}}} e^{-i \frac{2 \pi l_{2} j_{2}}{N_{2}}}\right.\right.\right.\right. \\
& \left.\left.\ldots e^{-i \frac{2 \pi \pi_{5} j_{5}}{N_{5}}}\right)\right) \ldots
\end{aligned}
$$

where

$$
\begin{aligned}
f\left(j_{1}, j_{2}, \ldots, j_{5}\right)= & \frac{1}{K_{1} K_{2} \ldots K_{5}} \sum_{l_{1}=-k_{1}}^{k_{1}-1}\left(\sum _ { l _ { 2 } = - k _ { 2 } } ^ { k _ { 2 } - 1 } \left(\ldots \left(\sum_{l_{5}=-k_{5}}^{k_{5}-1}\right.\right.\right. \\
& \left.\left.\left.\left(F\left(l_{1}, l_{2}, \ldots l_{5}\right) e^{-i \frac{2 \pi l_{1} j_{1}}{K_{1}}} e^{-i \frac{2 \pi l_{2} j_{2}}{K_{2}}} \ldots e^{-i \frac{2 \pi l_{5} j_{5}}{K_{5}}}\right)\right) \ldots\right)\right)
\end{aligned}
$$

$K_{m}(m=1,2 \ldots 5)$ is the node number for each dependency $\left(K_{m}=2 k_{m}-1\right)$ and the maximum harmonic number is $N_{m}=K_{m} / 2$.

We have applied the Fourier method separately for the three ionospheric regions: (1) $\mathrm{E}$ to bottomside of the $\mathrm{F}$ region $(95-180 \mathrm{~km}) ;(2)$ the $F$ region $(185-700 \mathrm{~km})$ and $(3)$ the topside ionosphere (710-1160 km). Even though sharing the matrix in three parts, it was necessary to use a high performance computer and parallel modeling to extract all Fourier coefficients.

In fact, the main advantage of such parameterization is to provide a friendly interface to the users with quick answers, for instance, for different geophysical conditions. In contrast, theoretical/physical model takes a long time to get convergence of its equations and to yield results to the users. 


\section{Results and discussion}

We analyze here some representative results of the theoretical climatology given by the new PARIM for the solar minimum month September 1997 and the solar maximum month October 2002. Figures 1 and 2 show the plasma frequency contours from the $E$ region to the bottomside F-region calculated by the SUPIM ( $1^{\text {st }}$ column) and PARIM ( $2^{\text {nd }}$ column) for $06\left(1^{\text {st }}\right.$ line $), 12\left(2^{\text {nd }}\right.$ line $)$ and 20 LT ( $3^{\text {rd }}$ line) during equinoxes of solar minimum and solar maximum, respectively. In general, the SUPIM values of the low-ionosphere plasma frequencies are very well reproduced by new PARIM for both solar minimum and solar maximum conditions. The $\mathrm{E}$ region plasma frequencies calculated by new PARIM have presented a latitudinal asymmetry, mainly during morning time, when the plasma frequency values are higher in the southern hemisphere. Since the SUPIM calculations were carried out in magnetic coordinates and considering that in the low ionosphere there is weak influence of the dynamic effects in comparison with photoionization and that the magnetic declination angle is $\sim-20^{\circ}$ in this region, such asymmetry can be explained by the earlier sunrise/photoionization in the southern hemisphere than in the northern hemisphere.

The plasma frequency contour maps of the $\mathrm{F}$ region (185$1160 \mathrm{~km}$ ) calculated by the SUPIM and new PARIM at 06, 12 and $20 \mathrm{LT}$ for equinoctial conditions of solar minimum

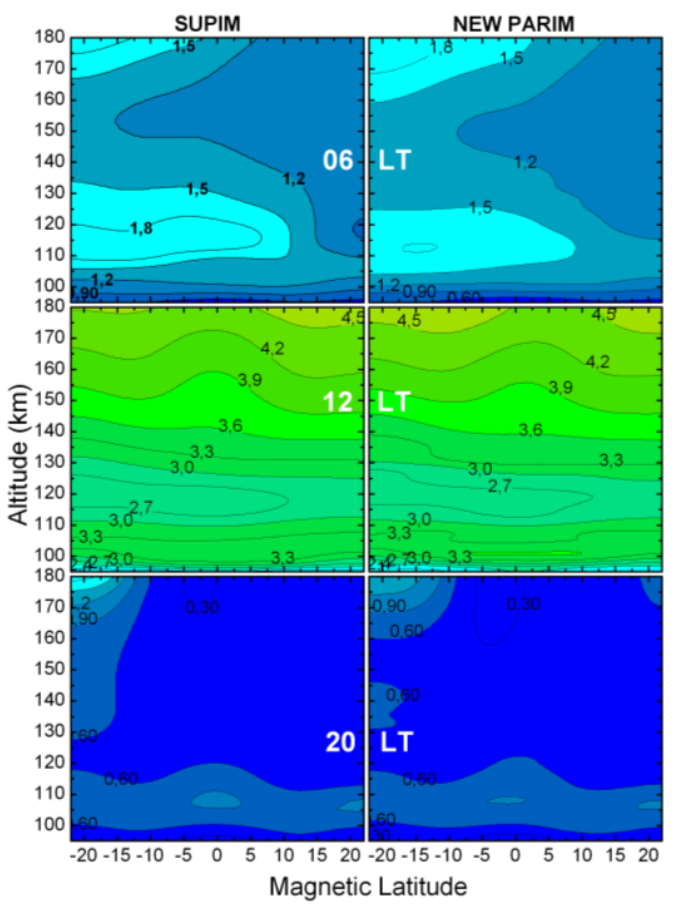

Figure 1. Magnetic meridional cross sections of the plasma frequency from $\mathrm{E}$ region to bottomside of the $\mathrm{F}$ region calculated by SUPIM and new PARIM for 06, 12 and 20 LT during equinox of solar minimum.

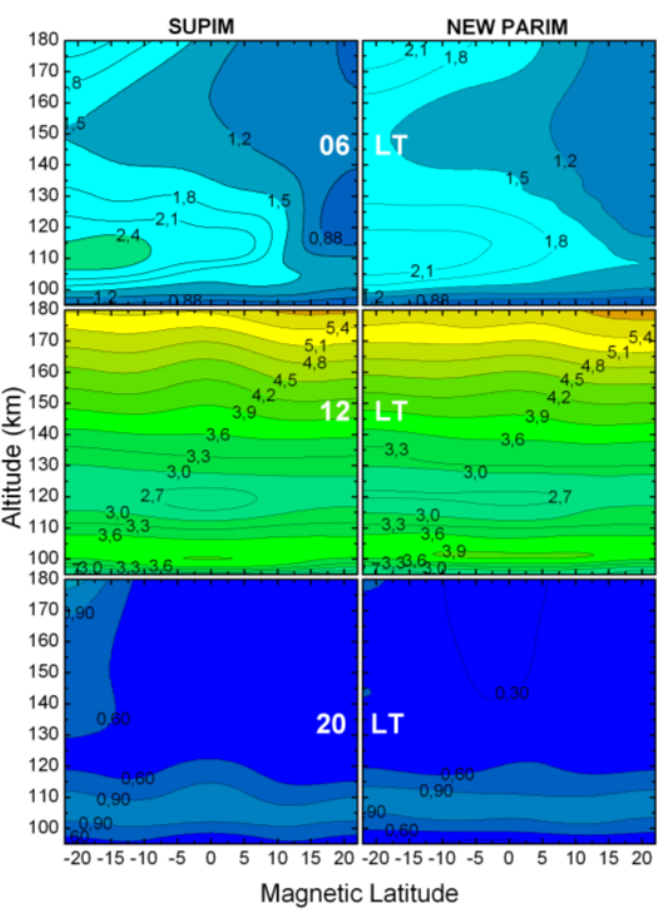

Figure 2. Same as Figure 1, but for solar maximum conditions.

and maximum are presented in the Figures 3 and 4, respectively. New PARIM presents good results (see for example, right hand side panels), i.e., the SUPIM values of the plasma frequencies are well reproduced, except for the not so well smoothed frequencies above the F-region peak in the morning and evening times. All the features of a low-latitude ionosphere, such as the equatorial anomaly evolution presented in the SUPIM results $\left(1^{\text {st }}\right.$ column in Figures 3 and 4) are well represented by the new PARIM. A fair comparison of the modeled results must be together with observed data. However, what we can see in the SUPIM results is an ionosphere governed by the driving forces under different geophysical conditions. At the evening time, due to the intensification of the fountain effect and the plasma control by the magnetic field, we can see in the SUPIM results a spatial plasma distribution nearly aligned with the magnetic field lines.

Figures 5 and 6 show the observed and modeled values of the critical frequencies and peak heights for the $E$ (foE and $\mathrm{hmE}$ ) and $\mathrm{F}$ regions (foF2 and $\mathrm{hmF} 2$ ), respectively. The data are representative of geomagnetically quiet equinoctial conditions of solar maximum (F10.7 $\approx 180$ ) and were simultaneously measured by digisondes at the Brazilian stations Boa Vista (magnetic latitude $=11$.), Cachimbo (magnetic latitude $=-1.8$ ) and Campo Grande (magnetic latitude $=-11$.) during the conjugate point equatorial experiment (COPEX) campaign (Reinisch et al., 2004; Abdu et al., (2004, 2009); Sobral et al., 2009). The values of foE calculated by the new PARIM (open circles) show excellent agreement with the data at all COPEX sites during daytime. Unfortunately, due to absorption processes the low E-region plasma frequency 


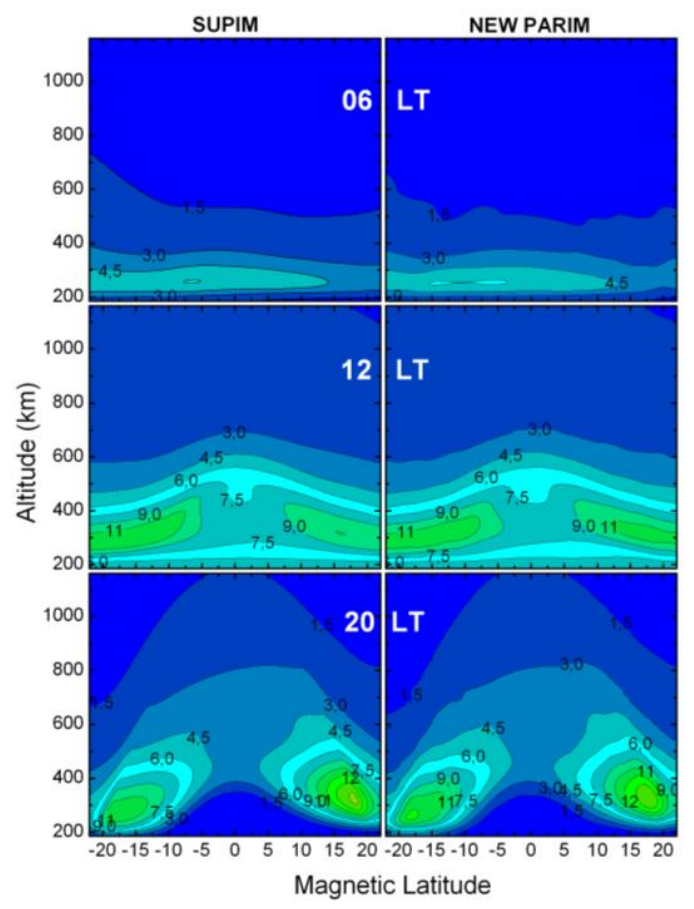

Figure 3. Magnetic meridional cross sections of the plasma frequency from $F$ region to topside of the F-region calculated by SUPIM and PARIM for 06, 12 and 20 LT during equinox of solar minimum.

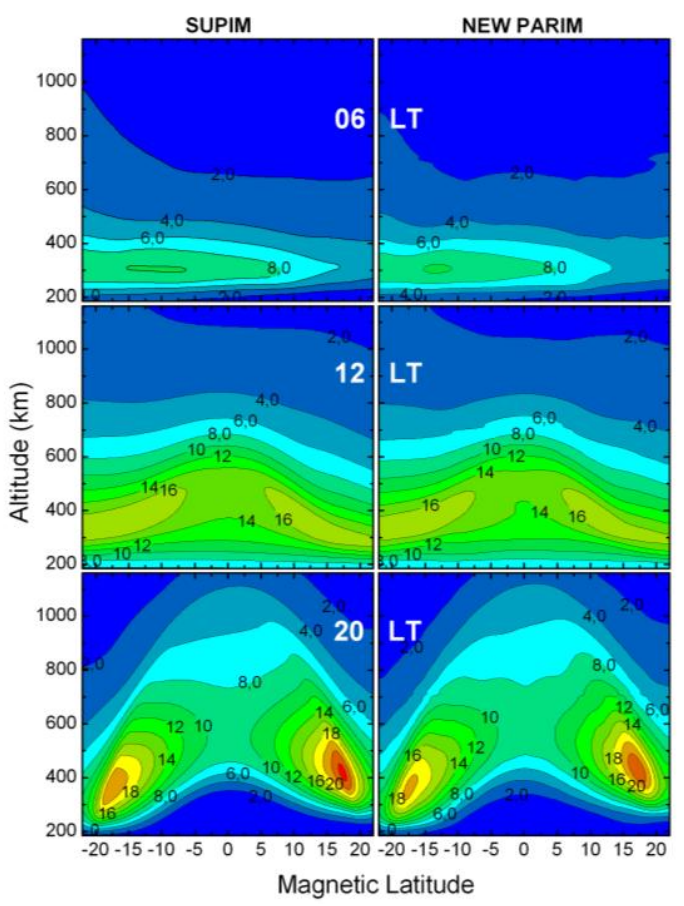

Figure 4. Same as Figure 3, but for solar maximum conditions.
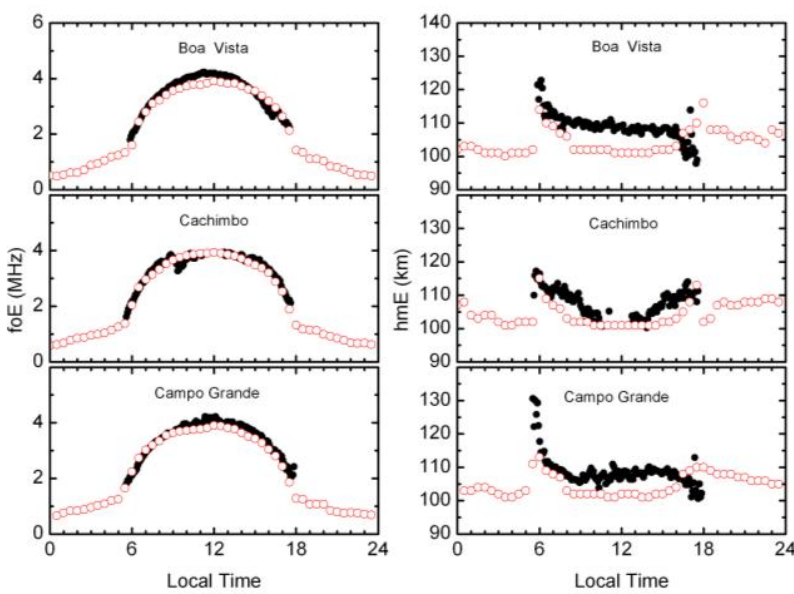

Figure 5. Comparison of the observed E-region critical frequency (foE) and its corresponding height (hmE) over the COPEX stations, Boa Vista, Cachimbo and Campo Grande with the values calculated by PARIM.
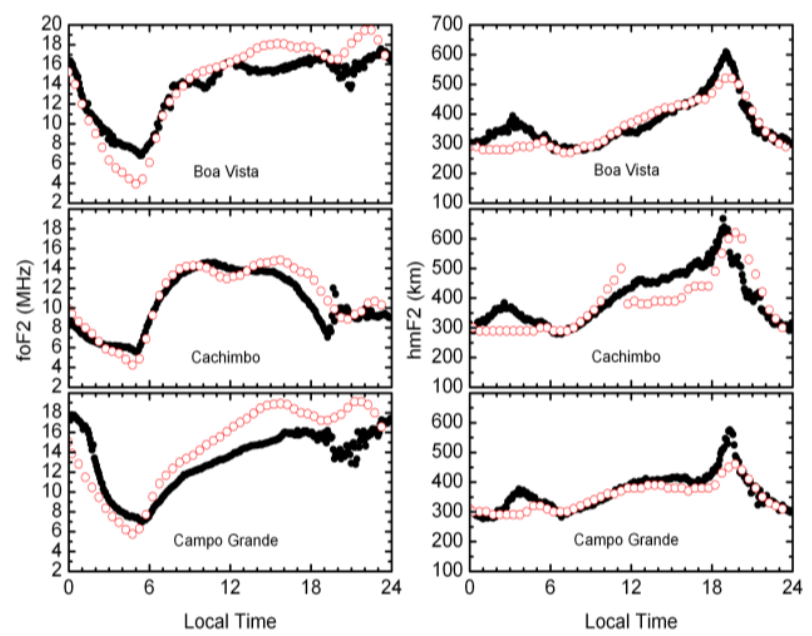

Figure 6. Same as Figure 5 but for F region.

cannot be registered by the digisondes during the evening-morning period. Both the observed hmE and that calculated by PARIM present abrupt changes near sunrise and sunset over all COPEX sites.

The F-region parameters, foF2 and hmF2 calculated by the new PARIM are in good agreement with the observations, but marked exceptions are seen during daytime over Boa Vista and Campo Grande, where the modeled values of the peak frequencies are overestimating (see Figure 6). The parameter hmF2 given by new PARIM shows a coherent discontinuity over the equatorial station Cachimbo near midday which correspond to the occurrence time of the $\mathrm{F}_{3}$ layer (Balan and Bailey, 1996). Since these hmF2 values were not well consistent in the old PARIM (Souza et al., 2010), this is an indication that the F-layer shape when influenced by the $F_{3}$ layer has being well represented by this new version. 


\section{Figure}

4.

Figure 3, but

for solar

maximum

conditions.

ire 7 shows longitudinal variation of TEC (Total crectron Content) over the American sector calculated by the vertical integration of the electron density obtained by PARIM second version at 18 UT for equinox condition and $F 10.7=180$. As we can see, the coherent latitudinal and longitudinal distributions of the ionization equatorial anomaly have been presented.

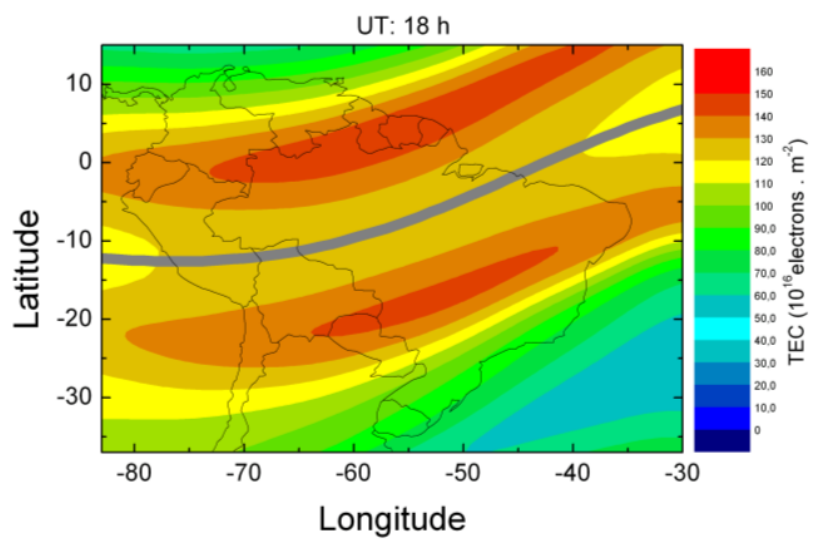

Figure 7. Longitudinal variation of TEC over the American sector calculated by PARIM second version at 18 UT for equinox and $\mathrm{F} 10.7=180$.

\section{Main Conclusions}

1. We have described a new version of our Parameterized Regional lonospheric Model (PARIM) to reproduce the ionospheric plasma frequencies (electron densities) as given by the SUPIM. This model version was constructed using multidimensional finite Fourier series. In general, the PARIM model produces very good results;

2. The E-region critical frequencies calculated by new PARIM and the IRI show excellent agreement with all the observational data from the COPEX campaign;

3. Both foF2 and hmF2 calculated by PARIM show good agreement with the observations, except during daytime over Boa Vista and Campo Grande;

4..Coherent latitudinal and longitudinal distribution of the TEC can be seen in the PARIM map for the Brazilian sector.

\section{Acknowledgments}

The authors wish to acknowledge the supports from the Fundação de Amparo a Pesquisa do Estado de São Paulo - FAPESP through the grants no. 2010/07437-7 and the Professor Graham Bailey from University of Sheffield for access to SUPIM source code.

\section{References}

Abdu, M.A, Batista, I.S, Reinisch, B.W., de Souza, J.R., de Paula, E.R., Sobral, J.H.A. and T. W. Bullet,T.W., Equatorial Spread $\mathrm{F}$ variability investigations in Brazil: Preliminary results from Conjugate Point Equatorial Experiments Campaign-COPEX, AGU spring meeting Montreal, 2004.
Abdu, M.A, Batista, I.S, Reinisch, B.W., de Souza, J.R., Sobral, J.H.A., Pedersen, T.R., Medeiros, A.F., Schunch, N.J., de Paula, E.R., Groves, K.M., Conjugate Point Equatorial Experiment (COPEX) Campaign in Brazil: Electrodynamics highlights on spread $F$ development conditions and day-to-day variability, J. Geophys. Res., 114, A04308, doi:10.1029/2008JA013749, 2009.

Bailey, G.J.; Sellek, R. A mathematical model of the Earth's plasmasphere and its application in a study of $\mathrm{He}^{+}$ at L=3. Annales Geophysicae, 8 (3), pp. 171-190, 1990.

Bailey, G.J.; Balan, N. A Low-Latitude IonospherePlasmasphere Model. Solar-Terrestrial Energy Program: Handbook of lonospheric Models, Ed. R.W. Schunk, pp. 173-206, 1996.

Bailey, G.J.; Balan, N.; Su, Y.Z. The Sheffield University lonosphere-Plasmasphere Model - A Review. J. Atmos. Terr. Phys., 59 (13), pp. 1541-1552, 1997.

Balan N., Bailey, G.J., Modelling studies of equatorial plasma fountain and equatorial anomaly. Adv. Space Res., 18(3):107-116, 1996.

Bishop, G.J., Daniell, R.E., Rao, S., Mazzella, A.J., Bullett, T.W., An application of parameterized real-time ionospheric specification model to regional ionospheric specification, Radio Science, 36(5), pp. 1255-1263, 2001.

Daniell, R.E., Brown, L.D., Anderson, D.N., Fox, M.W. Doherty, P.H., Decker, D.T., Sojka, J.J., Schunk, R.W. Parameterized ionospheric model: A global ionospheric parameterization based on first principles models, Radio Science, 30(5), pp. 1499-1510, 1995.

Nowak, R. 2D DFT, http://cnx.org/content/m10987, 2008.

Reinisch, B.W., Abdu, M.A., Batista, I.S., Sales, G.S., Khmyrov, G., Bullet, T.A., Chau, J. and Rios, R., Multistation digisonde observations of equatorial spread $\mathrm{F}$ in South America, Ann. Geophys., 22, pp. 3145-3153, 2004

Sobral, J.H.A, Abdu, M.A., Pedersen, T.R., Castilho, V.M., Arruda, D.C.S., Muella, M.T.A.H., Batista, I.S. Mascarenhas, M., de Paula, E.R., Kintner, P.M., Kherani, K.E., Medeiros, A.F., Buriti, R.A., Takahashi, H., Schuch, N.J., Denardini, C.M., Zamlutti, C.J., Pimenta, A., de Souza, J.R., Bertoni, F.C., lonospheric zonal velocities at conjugate points over South America: Experimental observations and theoretical validations during the COPEX campaign, J. Geophys. Res., 114, A04309, doi: 10.1029/2008JA013896, 2009.

Souza, J. R.; Brum, C. G. M.; Abdu, M. A.; Batista, I. S.; Asevedo Jr, W. D.; Bailey, G. J.; Bittencourt, J. A. Parameterized regional ionospheric model and a comparison of its results with experimental data and IRI representations, Adv. Space Res., 46, doi: 10.1016/j.asr.2009.11.025, 2010. 